\title{
Analysis of collagen preservation in bones recovered in archaeological contexts using NIR hyperspectral Imaging
}

\author{
Damien Vincke ${ }^{1}$, Rebecca Miller ${ }^{2}$, Édith Stassart ${ }^{2}$, Marcel Otte ${ }^{2}$, Pierre Dardenne ${ }^{1}$, Matthew \\ Collins $^{3}$, Keith Wilkinson ${ }^{4}$, John Stewart ${ }^{5}$, Vincent Baeten ${ }^{1}$, Juan Antonio Fernández Pierna ${ }^{1}$ *
}

1 Walloon Agricultural Research Centre, Valorisation of Agricultural Products Department, Henseval' Building, Chaussée de Namur, 24, 5030 Gembloux, BELGIUM

2 University of Liège, Service of Prehistory, 7, place du XX août, bâtiment A1, 4000 Liège, BELGIUM

3 University of York, Department of Archaeology, Wentworth Way, York, North Yorkshire YO10 5DD UNITED KINGDOM

4 University of Winchester, Department of Archaeology, Winchester SO22 4NR UNITED KINGDOM

5 Bournemouth University, Faculty of Science and Technology, Talbot Campus, Fern Barrow Poole, Dorset, BH12 5BB UNITED KINGDOM

* Corresponding author: fernandez@cra.wallonie.be 


\author{
Abbreviations \\ AMS: Accelerator Mass Spectrometry \\ NIR-HCl: Near Infrared Hyperspectral Chemical Imaging \\ ZooMS: Zoorchaeology by Mass Spectrometry
}

\title{
Keywords
}

Bone, Collagen, Near Infrared (NIR) Hyperspectral Imaging, Principal Component Analysis (PCA), Partial Least Squares-Discriminant Analysis (PLS-DA), Sorting

\section{Highlights}

- Specific and characteristic spectral bands of collagen in bones have been identified

- NIR imaging as a rapid, nondestructive technique to identify collagen preservation in bone.

- Chemometric and Imaging tools allow evaluation of collagen preservation in fossil bones

- Application of these techniques to analyze collagen preservation in bones from different geological strata in archaeological context at a single site is presented. 


\begin{abstract}
The scope of this article is to propose an innovative method based on Near Infrared Hyperspectral Chemical Imaging (NIR-HCl) to rapidly and non-destructively evaluate the relative degree of collagen preservation in bones recovered from archaeological contexts. This preliminary study has allowed the evaluation of the potential of the method using bone samples from the Early Upper Palaeolithic, Mesolithic and Neolithic periods at the site of Trou Al'Wesse in Belgium. NIR-HCl, combined with chemometric tools, has identified specific spectral bands characteristic of collagen. A chemometric model has been built using Partial Least Squares Discriminant Analysis (PLS-DA) to identify bones with and without collagen. This enables the evaluation of the degree of collagen preservation and homogeneity in bones within and between different strata, which has direct implications for archaeological applications (e.g., taphonomic analyses, assemblage integrity) and sample selection for subsequent analyses requiring collagen. Two archaeological applications are presented: comparison between sublayers in an Early Upper Paleolithic unit, and evaluation of the range of variability in collagen preservation within a single Holocene stratum.
\end{abstract}

\title{
Introduction
}

Archaeologists rely on a range of different data sources to reconstruct the past, including the artifacts and structures created by humans in the past, faunal and vegetal assemblages reflecting hunting, gathering, husbandry and cultivating activities, geological analysis of the deposits to determine deposition and post-depositional processes, dating of different materials to reconstruct the chronological framework, among others. Given the time depth and factors affecting the preservation of an archaeological site, these sources provide only partial information on past human behavior and the environmental context of human occupations. Due to recent progress in analytical methods (see e.g., [1]), archaeologists now have a range of new analyses to exploit information that could not previously be directly extracted. Bone has a complex composition which can be seen as a mix between a mineral (apatite) and an organic matrix (collagen). This composite material contains three major constituents: carbonated 
apatite crystal $\left(\mathrm{Ca}_{5}\left(\mathrm{PO}_{4}, \mathrm{CO}_{3}\right) 3(\mathrm{OH})\right)$, collagen and water. Collagen is the protein that constitutes the main part of bone organic matrix ([2-4]).

Many analyses used by archaeologists require collagen. These analyses include the Zooarchaeology by Mass Spectrometry (ZooMS) technique for taxonomic identification of even very small bone particles by comparison of the amino acid groupings contained in bone collagen ([5]-[6]), radiocarbon (AMS) dating of bone from archaeological contexts ([7]-[8]) and stable isotopic analyses to reconstruct past human and animal diets ([9]-[10]).

For these (and other) analyses, the challenge is to obtain bone samples with sufficient collagen content to obtain positive results. To date, there has been no protocol or analytic method capable of rapidly and non-destructively screening bones to detect and quantify collagen. Techniques are therefore needed to deal with large numbers of samples and with the potential of direct measurement on-site.

Initial results obtained during the first phase of the ArcheoNIR project, presented here, appear to show that spectroscopy techniques such as Near Infrared (NIR) and NIR hyperspectral chemical imaging (NIR-HCl) can be applied to meet these needs. Such technologies could potentially revolutionize the analysis of sediments in cave and open-air sites and bones by revealing far more detailed records of the contexts of human occupations.

Both techniques have been successfully applied in agronomy for the detection of meat and bone meal in animal feed to help prevent Bovine Spongiform Encephalopathy (BSE) [11]. However, only a few studies have applied NIR analyses to bones from archaeological contexts, showing, however, that these can provide a wide range of information concerning the classification of archaeological soil samples [12] or the burial history of bones/diagenesis [13], which have also been analyzed by Mid Infrared (MIR) [14-15] and Raman [16] spectroscopy. Other studies have investigated collagen in blood vessels or muscles using NIR spectroscopy [1718]. For hyperspectral imaging, very few applications have been attempted in archaeology (see e.g., [19-20], [12]), but not at the scale of assemblage or artifact and none on bone or collagen. Another potential field of application for hyperspectral imaging is soil analysis ([21-26]). In this context, the aim of the ArcheoNIR project is to combine archaeometric and archaeological analyses, testing the application of near-infrared spectroscopy (NIRS) combined 
with hyperspectral chemical imaging (NIR-HCl) to faunal samples from the Pleistocene and Holocene sequence at the Belgian archaeological site of Trou Al'Wesse [27-29]. NIR-HCl is used to screen bones recovered during excavations and test the model developed to evaluate the degree of collagen preservation. Taphonomy is the study of the processes from the time of death of an organism to its retrieval. In archaeology this is extended to include the analysis of site taphonomy referring to the processes of deposition and those occurring after deposition that mechanically and/or chemically alter the archaeological material, including the sediments themselves. Taphonomic analysis of a site considers several lines of evidence to evaluate and interpret the context in which the artifacts were excavated. $\mathrm{NIR-HCl}$ analysis of bone samples within and between strata provides new taphonomic data with respect to processes affecting bone and collagen preservation and thus contributes to understanding of site formation processes and factors affecting the archaeological record. Finally, $\mathrm{NIR}-\mathrm{HCl}$ can be used as a decision-making tool to evaluate whether collagen content of bone samples is sufficient for further analyses requiring collagen.

\section{Materials and methods}

\section{Archaeological site}

The Pleistocene-Holocene stratigraphic sequence of Trou Al'Wesse covers the period from ca. 50,000 to 5,000 uncal BP (uncalibrated years before present) and includes human occupations from the Mousterian, Aurignacian, Mesolithic and Neolithic periods. Non-archaeological layers, one intermediate between the Mousterian and Aurignacian, and others covering the Last Glacial Maximum and early Late Glacial, also contain faunal assemblages. This long archaeological sequence enables us to address one of the main questions in current research: the effect of climate change on human occupation during the Palaeolithic and Early Holocene. Climate and environment play a key role in explanations of human adaptation, survival and extinction when hominids are confronted with change [30]. NIRS-HCl analyses of the fauna will contribute to these questions by clarifying differences in faunal taphonomy within and between strata, leading to further analyses that will refine our understanding of palaeoenvironmental and climatic change observed within a single sediment sequence. At Trou Al'Wesse, ongoing ancient 
DNA analyses of fauna (see e.g., [31-32]) may benefit in the near future from appraisal of potential samples by NIRS-HCl analyses.

\section{Instrumentation}

In this work, a NIR hyperspectral line scan or push-broom imaging system combined with a conveyor belt (BurgerMetrics SIA, Riga, Latvia) was used (Figure 1a and b). The instrument is a SWIR XEVA CL 2.5320 TE4 camera (Specim Ltd, Oulu, Finland); using an ImSpector N25E spectrograph that includes a cooled, temperature-stabilized Mercury-Cadmium-Telluride (MCT) detector (Xenics nv, Leuven, Belgium). The system projects a beam of light onto a twodimensional Focal Plane Array (FPA) and each image consists of 320-pixel lines acquired with 209 wavelength channels: 1,100-2,400 nm with a wavelength interval of $6.3 \mathrm{~nm}$. 32 scans per image have been averaged and each pixel provides a reflectance spectrum of a point on the bone specimen. Acquisition is done using HyperProVB software (BurgerMetrics SIA, Riga, Latvia).

Prior to analysis, the spectral NIR imaging system is calibrated with a dark image (by shutting off the lens entrance) and a white image (background) collected from a standard white reference board (empty teflon plate). The spectra are then automatically corrected. This procedure is performed to compensate for offset due to the dark current, the light source temperature drift, and the lack of spatial lighting uniformity.

Once the spectral library is built, chemometric analyses can be performed, including PCA (Principal Components Analysis) and PLS-DA (Partial Least Square Discriminant Analysis). These analyses allow extraction of the maximum amount of information from the raw data [33], prior to comparison of different areas on a single bone, bones from a single stratum, bones from different strata, etc.

Figure 1

\section{Sample selection}

The bone specimens used for the calibration and validation sets to build the model are all small fragments, on average, $27 \mathrm{~mm}$ long, $14 \mathrm{~mm}$ wide and $5 \mathrm{~mm}$ thick (size ranges: length 12-47 $\mathrm{mm}$, width 6-24 mm, thickness 1-9 mm). For many of the samples, one side is the external 
surface of the cortical bone of longbone fragments, the other the interior; other samples are flat bones (e.g., rib fragments) where both sides are external. Since collagen may not be uniformly distributed throughout a bone, both sides of a specimen were scanned. All are relatively flat, some with a very slight curve. Archaeological bones (and other artifacts) to $1 \mathrm{~cm}$ are recorded in situ during excavation and include bone fragments and larger, more complete bones. Water sieving of the sediments additionally permits recovery of small complete and fragmentary bones, particularly of small rodents, birds, fish, etc. The bone samples used for this paper are all larger mammal bone fragments recovered in situ. The smaller fragmentary bones of these were selected as these are much more common in an archaeological assemblage than complete bones and are often unidentifiable (anatomical element, species); evaluation of collagen preservation enables them to be sent for specialized analyses, such as ZooMS or ancient DNA, that could lead to identification. The samples used were cleaned with water only and air dried. Bone is originally damp from the sediments in which they were found, but not water-logged; all have been air dried to the same humidity level. NIRS and HIS analyses took place well after excavation and processing, samples used in the present paper were excavated in from 2005 to 2009.

After image acquisition, individual spectral libraries are created for each bone scanned using the HyperSee software (BurgerMetrics SIA, Riga, Latvia). Each library contains 50 spectra selected at random places on the bone. The selection of spectra is made in such a way to cover the range of spectral diversity on the bone surface and also takes into account the variability between the different sides of the bone. For this, on each side of the bone, subsampling is done by selecting 5 pixels of interest (assuring maximum variability) as well as the four neighbours, i.e. 25 spectra per side. Both sides of the bones were analyzed because the penetration depth of the radiation with this instrument is only a few $\mu \mathrm{m}$.

After collection of the spectral library, a sample set to be used for building models for collagen detection is created and randomly split into a calibration and a validation set. The calibration set comprises 800 spectra coming from 16 different bone samples grouped in two classes. The success or failure of AMS dating of bones from Trou Al'Wesse prior to the present study and their geological context (alluvial [stream deposits] or colluvial [slope deposits]) were used as 
criteria to define two classes of bones that have sufficient collagen (successful AMS dating, colluvial layers) or would have little or no collagen (failed AMS dating, alluvial layers). The first class $(\mathrm{COL}+)$ includes bones from two Mesolithic strata that were not subject to collagen decay (successful AMS dating, colluvial layers). Bones from this layer are assumed to have good collagen preservation, sufficient for successful AMS dating and thus, by extension, for other analyses requiring collagen as well, such as ZooMS, stable isotope analysis and potentially ancient DNA. The second class (COL-) comprises bones from two Mesolithic strata subject to recurrent water flooding (failed AMS dates, alluvial layers). Such flooding may have removed most or all of the collagen. The validation set, independent from the calibration set, contains 200 spectra from four additional samples, two each from the "COL+" and "COL-" classes and from the same layers as the calibration set. This sample set is used to validate the calibration model by predicting presence or absence of collagen. The model design and sample selection process is shown in a synthetic diagram (Figure 2).

Figure 2

For comparison an external independent validation standard was provided by the University of York, a medieval cow tibia (Figure 3). Analysis of this sample at York indicated that collagen preservation was close to modern levels and it had lost the lipids found in modern bones [34].

Figure 3

\section{Model design}

Two models were constructed for the present study: a PCA and a PLS-DA model. Both models were created using the Matlab software (The MathWorks, Inc., Natick, MA, USA) and the PLS Toolbox (Eigenvector Research, Inc., Wenatchee, WA, USA).

Pre-processing of the data was applied for both models to remove scattering and other nonchemical effects from the spectra. For the PCA model, a first derivative was applied using the Savitzky-Golay algorithm with a polynomial order of 2 and a window of 15 points. 
Two preliminary archaeological applications were done to test the model: comparison of sublayer in an Early Upper Paleolithic unit, and evaluation of the range of variability in collagen preservation within a single Holocene stratum.

\section{Identification/confirmation of geological stratification}

In 2012, one of the aims of the field season was to examine Early Upper Palaeolithic stratigraphic unit 15, dated between ca. 26,000 and 40,000 BP, which contains evidence of an Aurignacian human presence, and to identify potential geological sub-divisions. Vertical excavation of a $25 \mathrm{~cm}$ wide band in unit 15 led to the identification of nine distinct sub-layers in the field, based on geological variables. Nine bones (one for each sub-layer) were processed with the PLS-DA model and screened for potential variation or groups between samples. These are currently being dated by AMS using ultrafiltration at the Oxford Radiocarbon Accelerator Unit dating lab.

\section{Comparison within and between layers}

Bones found within a single stratum may have been subject to different post-depositional processes leading to differential degradation or intensity of decay; these include chemical processes that can cause removal of collagen and/or mechanical processes that can cause bone fragmentation. Such taphonomic variability may be linked to, among others, the past environmental conditions, the length of exposure of bone prior to burial, movement of bone (by water, erosion, etc.). Comparing bones from a single stratum provides information on range of variability in collagen preservation and thus the post-depositional processes that affected the stratum. Comparison of sample sets from two different strata can therefore be done to evaluate the degree of similarity/difference between them and provide further support for geological distinction.

Bones from two layers were selected to analyze the collagen homogeneity within and between each layer. The first series of samples was selected from stratum AC, classified as COL-. The second sample set contains bones from a Holocene stratum with no preliminary information available on collagen content (stratum 4a). The choice for the latter was based on evidence of human occupation attributing it to the Middle Neolithic. 50 bones were selected from each layer and for each of these bones 50 spectra were extracted ( 25 spectra per side), making a 
total of 2550 spectra collected per stratum. Next, the 2550 spectra from each layer were analyzed using the PLS-DA model to obtain the prediction score of each spectrum. The prediction scores of the spectra from a single sample were then pooled to compute the mean prediction score of the sample and its estimated standard deviation (confidence level of 95\%).

\section{Preliminary results and discussion}

Figure 4

In their paper, Baykal et al. [17] discuss characteristic wavelengths related to the presence of collagen in samples analyzed in the NIR range. Figure 4 presents the mean spectra of samples from COL+ and COL- classes used for the model construction. The medieval cow sample is also included to show the potential wavelengths of interest for collagen detection. As can be seen, a drift in absorbance is visible in the figure: samples with higher collagen content seem to have higher absorbance values. This drift could be linked to the higher level of organic matter present in bones with collagen compared to bones without collagen. Such drift should be further studied to explain its occurrence.

Comparison between the data presented in Baykal et al. [17] and spectra from the COL+ class and the medieval cow appears to show similar characteristic wavelengths (vertical lines in Figure 4). Further, spectral comparison between COL+ and COL- samples seems to indicate the potential for segregation. Figure $\mathbf{5}$ shows the spectral differences between COL+ and COLsamples. Figure 5a was obtained after applying a first derivative using the Savitzky-Golay algorithm with a polynomial order of 2 and a window of 15 points, and Figure $5 \mathrm{~b}$ after applying a second derivative using the Savitzky-Golay algorithm with the same parameters. The spectral difference is particularly clear in the $2000-2400 \mathrm{~nm}$ range. These observations are promising for model building to sort the samples by presence/absence of collagen.

Figure 5 


\section{Model design}

The PCA model carried out on the calibration and validation sets provides good separation between COL+ and COL- samples (Figure 6a). The scatter plot of PC1 against PC2 clearly indicates a better separation on the second component (PC2). Overall, positive PC2 scores (top of the graph) can be attributed to $\mathrm{COL}+$ samples and negative PC2 scores (bottom of the graph) to COL- samples. The analysis of the loadings for PC1 (Figure $6 \mathrm{~b}$ ) indicates two wavelengths of influence at $1410 \mathrm{~nm}$ and $1910 \mathrm{~nm}$, which are within the absorption bands of the $\mathrm{O}-\mathrm{H}$ bond [35]. These observations suggest that PC1 does not discriminate the samples according to their collagen content, but may be linked to the $\mathrm{O}-\mathrm{H}$ bond of the carbonated crystal apatite, or to the water content of the samples.

\section{Figure 6}

Figure 7

Loadings on PC2 were then plotted (Figure 7) to visualize the wavelengths responsible for the separation between $\mathrm{COL}+$ and $\mathrm{COL}-$ samples. The loadings of a model are the respective weights of each wavelength in the model. Wavelengths with high loading values (in absolute value) are the ones that most influence the model.

As we have good separation along PC2, the positive values in the loading plot for PC2 can be linked to the positive PC2 values of the PCA scatter plot. These positive values are mostly the values for COL+ samples. By using this analysis method, the loadings report three influent wavelengths that could potentially be linked to collagen. These wavelengths are $1430 \mathrm{~nm}(\mathrm{~N}-\mathrm{H}$ first overtone), $2030 \mathrm{~nm}$ ( $\mathrm{C}=\mathrm{O}$ stretching second overtone) and $2150 \mathrm{~nm}$ (amide I + amide II) [35]. These three wavelengths are linked to chemical bonds that are typical for protein. As collagen is the most abundant protein in bones, there would appear to be a direct link between these wavelengths and the presence of collagen. In addition, the 2030 and $2150 \mathrm{~nm}$ peaks are also consistent with the spectra presented by Baykal et al. [17]. In addition, the possibility of 
interference of water absorbed by the samples can be rejected since all samples are at the same low humidity level.

To control the influence of the latter two wavelengths, another PCA was carried out on the same data with a restricted spectral range, from 1800 to $2300 \mathrm{~nm}$. The PCA scatter plot still provided a good separation, with positive PC2 values for COL+ samples, and the 2030 and 2150 $n m$ positive peaks are still observed in the loadings plot of PC2.

The results obtained with the PCA method were considered sufficiently good to attempt the design of a PLS-DA model. The preprocessing applied to the raw spectra was a Savitzky-Golay first derivative with the same parameters used in the PCA model and a cross validation step was applied. The maximum number of latent variables for the model was set at 8 .

The confusion matrix of the model is presented in Table $\mathbf{1}$ for the validation set. This matrix summarizes the results of the PLS-DA classification by showing the results of the prediction compared to the actual value of the spectra.

\section{Table 1}

The same results can also be demonstrated more visually in Figure 8. A spectrum from COL+ (triangles) below the grey dashed line would mean that the spectrum is predicted as COLinstead of $\mathrm{COL}+$, that is, a false negative result. In contrast, a COL- spectrum (stars) above the grey dashed line would mean that the spectrum is predicted as COL+ instead of COL-, or a false positive result. As we can see, regarding both Figure 8 and Table 1, the model seems to report no bad detection (false positive or negative).

In addition, a reduction of the spectral range was applied, from 1800 to $2300 \mathrm{~nm}$ as for the PCA model, to confirm the influence of this band for the detection of collagen. All the COL+ spectra were still detected (no false negative result) and only five out of the $100 \mathrm{COL}$ - spectra were detected as COL+ (false positive results). This suggests that the spectral band between 1800 $2300 \mathrm{~nm}$ has a high contribution to the discrimination of collagen in bones. Despite the good performances obtained with the restricted range model, these were slightly lower compared to 
the full range model. For this reason, the model with the full spectral range has been used in the present study.

\section{Figure 8}

\section{Taphonomy}

1. Model development. The models developed compared samples considered to have $(\mathrm{COL}+)$ or lack (COL-) collagen from four strata at Trou Al'Wesse: alluvial strata AC and ACOF (COL-), and colluvial strata $4 \mathrm{~b}-\delta$ and $4 \mathrm{~b}-\mathrm{LaH}(\mathrm{COL}+)$. All are Mesolithic in age, based on AMS dates obtained and analysis of the lithic assemblages. These results are thus not independent of the archaeological context.

Figure 9 shows the prediction of the medieval cow sample in the PLS-DA model. The model tends to sort the sample in the same class as samples from $\mathrm{COL}+$ class. The model is thus validated with an external reference of known high collagen content.

Figure 9

\section{Identification/confirmation of geological stratification}

The initial results of the PLS-DA predictions applied to the detection of geological stratification within Pleistocene stratigraphic unit 15 (Figure 10) seem to be much more nuanced. One sample from each of the sub-layers was analyzed $(n=9)$. Each sample is represented on the right side of Figure 10 by a vertical distribution where each point is the prediction score of one spectrum extracted from the image of the sample. Two samples appear to contain preserved collagen and are sorted in the COL+ class (grey stars and dark circles, or sub-layers 15.3 and 15.4). For the remaining seven samples, the prediction is more complex as they overlap the threshold of COL+/COL- classes. In the case of the nuanced samples, the predictions appear equally distributed on each side of the discrimination line of the model (black dashed line). This is due to variability in collagen presence/absence across the surface of each of these specimens, preventing clear separation into COL+ or COL- classes, which can be done when the range in 
spectra falls entirely above or below the threshold. Moreover, when conducting the analysis, including the external validation reference sample (medieval cow tibia), the errors obtained correspond to the limits of detection of the technique and model. This may be related to the age of the samples $(40-30,000$ versus $9-5,000$ years ago) or to other factors that need to be determined. To address these issues, larger sample sets from these sub-layers are being analyzed and will be discussed in a forthcoming publication (Miller et al., in prep.).

Figure 10

In order to take into account the potential variability of collagen content on a bone's surface, predictions were redone for the entire surface and on both sides of the bones instead of a sampling of 50 spectra per specimen. A total of 247,300 spectra (representing the entire surface of all nine samples) was processed by the model, confirming the results obtained with the first sampling method.

The predictions suggest that two specimens from layer 15 are similar to $\mathrm{COL}+$ samples while the others remain uncertain. These observations show variability between the different sub-layers of layer 15 and are promising, but further work needs to be done to allow interpretation.

\section{Layer comparisons}

The mean prediction score of each bone from COL- layer (stratum AC) (Figure 11) and stratum 4a, with unknown collagen content (Figure 12), is plotted with its confidence interval.

These prediction results (Figure 11-Figure 12), seem to indicate good homogeneity in collagen content as most of the samples within a single layer are found on the same side of the prediction threshold. Outlier values were found for three samples within the COL- layer. These samples were removed from the dataset to lower the noise in the display of the prediction results. In Figure 11 almost all the samples are sorted under the prediction threshold (dashed line), meaning that they are sorted into the COL- class which is consistent with the expected results; the single $\mathrm{COL}+$ sample, located at the upper interface between stratum $A C$ and overlying $4 \mathrm{~b}$-delta, has been determined to belong to stratum 4b-delta (R.M., pers. obs.); it can thus be eliminated from the AC sample set. In Figure 12 almost all the samples are above the 
prediction threshold, meaning that the model sorted them into the $\mathrm{COL}+$ class, suggesting that bones from this layer have good collagen preservation. Most of the samples in both figures have only a small dispersion of their prediction values, particularly in the case of the layer with unknown collagen content. This suggests that collagen content does not vary significantly within bones in these strata.

Figure 11

Figure 12

\section{Conclusion}

The overall objective of this work was to propose a new method based on $\mathrm{NIR}-\mathrm{HCl}$ to evaluate the relative degree of collagen preservation in bone recovered from archaeological contexts. This preliminary study has enabled evaluation of the potential of the method using bone samples from the Early Upper Palaeolithic, Mesolithic and Neolithic periods at Trou Al'Wesse in Belgium. NIR-HCl combined with chemometric tools have detected specific spectral bands characteristic of collagen, which enables analysis of the degree of collagen homogeneity within and between different strata. Identification of factors affecting the degree of collagen preservation, such as the presence of water and other post-depositional processes, help to clarify the site formation processes at an archaeological site and have direct implications for archaeological applications: faunal assemblage integrity, taphonomy and sample selection for subsequent analyses requiring collagen preservation, including ancient DNA, radiometric dating and ZooMS. However, further research is needed in order to evaluate the qualitative and/or quantitative degree of collagen preservation in archaeological bone. 


\section{Bibliographic references}

[1] Hofreiter M., Collins M. and Stewart J. R., 2012. Ancient biomolecules in Quaternary palaeoecology. Quaternary Science Reviews, 33, p. 1-13.

[2] Collins M. J., Hiller J., Smith C. I., Roberts J. P., Prigodich R. V., Wess T. J., Millard A. R. and Turner-Walker G., 2002. The survival of organic matter in bone: a review. Archaeometry, 44(3), 383-394.

[3] Polomska M., Kubisz L., Kalawski R., Oszkinis G., Filipiak R. and Mazurek A., 2010. Fourier transform near infrared Raman spectroscopy in studies on connective tissue. Acoustic and Biomedical Engineering, 118 (1), 136-140.

[4] Weiner S. \& Wagner H. D., 1998. The material bone: structure-mechanical function relations. Annual Review of Materials science, 98, 271-298.

[5] van Doorn N. L., Hollund H. and Collins M. J., 2011. A novel and non-destructive approach for ZooMS analysis: ammonium bicarbonate buffer extraction. Archaeological and Anthropological Science, 3 (3), 281-289.

[6] van Doorn N. L., Wilson J., Hollund H., Soressi M. and Collins M. J., 2012. Site-specific deamidation of glutamine: a new marker of bone collagen deterioration. Rapid Communications in Mass Spectrometry, 26, 2319-2327.

[7] Bowman S., 1990. Radiocarbon Dating. Interpreting the Past series, University of California Press, Berkley and Los Angeles. 64 pp.

[8] Davies E., 2010. The bones of it. Chemistry World, 44-48.

[9] Drucker D., Bocherens H., Mariotti A, Lévêque F., Vandermeersch B. and Guadelli J.-L., 1999. Conservation des signatures isotopiques du collagène d'os et de dents du Pléistocène supérieur (Saint-Césaire, France) : implications pour les reconstitutions des régimes alimentaires des néandertaliens. Bulletins et Mémoires de la Société d'Anthropologie de Paris, Nouvelle Série, tome 11 fascicule 3-4, pp. 289-305.

[10] Honch N. V., McCullagh J. S. O. and Hedges R. E. M., 2012. Variation of Bone Collagen Amino Acid $\delta^{13} \mathrm{C}$ Values in Archaeological Humans and Fauna with Different Dietary Regimes: Developing Frameworks of Dietary Discrimination. American Journal of Physical Anthropology, 148, pp. 495-511. 
[11] Fernández Pierna J. A., Dardenne P. \& Baeten V., 2010. In-house validation of a near infrared hyperspectral imaging method for detecting preprocessed animal proteins in compound feed, Journal of Near Infrared Spectroscopy, 18, pp. 121-133.

[12] Linderholm J. \& Geladi P., 2012. Classification of archaeological soil and sediment samples using near infrared techniques. NIR news, 23 (7), 6-9.

[13] Thomas D. B. , McGoverin C. M., Chinsamy A. and Manley M., 2011. Near infrared analysis of fossil bone from the Western Cape of South Africa. Journal of Near Infrared Spectroscopy, 19, 151-159.

[14] Lebon M., Müller K., Bahain J.-J., Fröhlich F., Falguères C., Bertrand L., Sandt C. and Reiche I., 2011. Imaging fossil bone alterations at the microscale by SR-FTIR microspectroscopy. Journal of Analytical Atomic Spectrometry, 26, 922-929.

[15] Stathopoulou E. T., Psycharis V., Chryssikos G. D., Gionis V. and Theodorou G., 2008. Bone diagenesis: New data from infrared spectroscopy and $X$-ray diffraction. Palaeogeography, Palaeoclimatology, Palaeoecology, 266, 168-174.

[16] Thomas D. B., Fordyce R. E., Frew R. D. and Gordon, 2007. A rapid, non-destructive method of detecting diagenetic alteration in fossil bone using Raman spectroscopy. Journal of Raman Spectroscopy, 38, 1533-1537.

[17] Baykal D., Irrechukwu O., Lin P.-C., Fritton K., Spencer R. G. and Pleshko N., 2010. Nondestructive Assessment of Engineered Cartilage Constructs Using Near-Infrared Spectroscopy, Society for Applied Spectroscopy, 64(10), pp. 1160-1166.

[18] Urbas A., Manning M. W., Daugherty A., Cassis L. A. and Lodder R. A., 2003. NearInfrared Spectrometry of Abdominal Aortic Aneurysm in the ApoE-/- Mouse. Analytical chemistry, 75(14), 3650-3655.

[19] Grøn O., Palmér S., Stylegar F.-A., Esbensen K., Kucheryavski S. and Aase S., 2011. Interpretation of archaeological small-scale features in spectral images. Journal of Archaeological Science, 38, 2024-2030.

[20] Savage S. H., Levy T. E. and Jones I. W., 2012. Prospects and problems in the use of hyperspectral imagery for archaeological remote sensing: a case study from the Faynan copper mining district, Jordan. Journal of Archaeological Science, 39, 407-420. 
[21] Holliday V. T. and Gartner W. G., 2007. Methods of soil P analysis in archaeology. Journal of Archaeological Science, 34, 301-333.

[22] Maleki M. R., Mouazena A. M., De Ketelaerea B., Ramona H. and De Baerdemaekera J., 2008. On-the-go variable-rate phosphorus fertilisation based on a visible and nearinfrared soil sensor. Biosystems Engineering, 99, 35-46.

[23] Mouazen A. M., Maleki M. R., De Baerdemaeker J. and Ramon H., 2007. On-line measurement of some selected soil properties using a VIS-NIR sensor. Soil and Tillage Research, 93, 13-27.

[24] Viscarra Rossel R. A., Walvoort D. J. J., McBratney A. B., Janik L. J. and Skjemstad J. O., 2006. Visible, near infrared, mid infrared or combined diffuse reflectance spectroscopy for simultaneous assessment of various soil properties. Geoderma, 131, 59-75.

[25] Steffens M. and Buddenbaum H., 2013. Laboratory imaging spectroscopy of a stagnic Luvisol profile - High resolution soil characterisation, classification and mapping of elemental concentrations. Geoderma, 195-196, 122-132.

[26] Viscarra Rossel R. A., Fouad Y., Walter. C., 2008. Using a digital camera to measure soil organic carbon and iron contents. Biosystems Engineering, 100, 149-159.

[27] Miller R., Zwyns N., Stewart J., Otte M. and Noiret P., 2005. La séquence holocène du Trou Al'Wesse : géologie, archéologie et environnement. Notae Praehistoricae, 25, 129144.

[28] Miller R., Zwyns N., Otte M., Stevens C. and Stewart J., 2012. La séquence mésolithique et néolithique du Trou Al'Wesse (Belgique) : résultats pluridisciplinaires. L'Anthropologie, $116,99-126$.

[29] Pirson S. \& Collin F., 2005. Contribution à la stratigraphie du Trou Al'Wesse à PetitModave (comm. de Modave, prov. de Liège). Notae Praehistoricae, 25, 39-47.

[30] Stewart J. R. \& Stringer C. B., 2012. Human Evolution Out of Africa: TheRole of Refugia and Climate Change. Science, 335, 1317-1321.

[31] Brace S., Palkopoulou E., Dalén L., Lister A., Miller R., Otte M., Germonpré M., Blockley S., Stewart J., \& Barnes I., 2012. Serial population extinctions in a small mammal indicate Late Pleistocene ecosystem instability. PNAS 109(50), pp. 20532-20536. 
[32] Meiri, M., Lister, A. M., Higham, T. F. G., Stewart, J. R., Straus, L. G., Obermaier, H., González Morales, M. R., Marín-Arroyo, A. B. and Barnes, I., 2013. Late-glacial recolonization and phylogeography of European red deer (Cervus elaphus L.). Molecular Ecology. Volume 22, Issue 18, 4711-4722.

[33] Fernández Pierna J. A., Baeten V. and Dardenne P., Dubois J., Lewis E. N. and Burger J., 2009. Spectroscopic imaging. In: Brown S., Tauler R., Walczak R. (eds.) Comprehensive Chemometrics, volume 4 pp. 173-196 Oxford: Elsevier.

[34] Ottoni, C., Koon H. E. C., Collins, M. J., Penkman, K. E. H., Rickards, O., Craig, O. E., 2009. Preservation of ancient DNA in thermally damaged archaeological bone. Naturwissenschaften. 96, 267-278.

[35] Osborne B. G. \& Fearn T., 1986. Near infrared spectroscopy in food analysis. Longman Group UK Limited, Burnt Mill, Harlow, Essex CM20 2JE, England. 200 pp.

\section{Acknowledgements}

The ArcheoNIR project is funded by the Fonds de la Recherche Scientifique (FNRS), Fonds de la recherche Fondamentale Collective (FRFC), project number F.FRFC 2.4621.12. The Trou Al'Wesse project, directed by Rebecca Miller and Marcel Otte (University of Liège, Service of Prehistory, Belgium), is supported by annual subsidies (02/16341 to $13 / 19227)$ granted by the Service public de Wallonie (SPW). We are also grateful to Ouissam Abbas (CRA-W) and the technical staff of all of the teams. 


\section{Figure captions}

Figure 1: Instrument used for image acquisition (a) and image acquisition configuration, sample on the conveyor belt (b).

Figure 2: Synthetic diagram for model design and sample selection (AC \& ACOF = alluvial layers; $4 b-\mathrm{LaH} \& 4 \mathrm{~b}-\delta=$ colluvial layers).

Figure 3: Photos of the medieval cow tibia sample (scale in $\mathrm{cm}$ ).

Figure 4: Mean spectra of samples from COL+ class, COL- class and medieval cow tibia.

Figure 5: Spectral differences in preprocessed spectra between COL- and COL+ samples: (a) first derivative and (b) second derivative.

Figure 6: PCA model, scatter plot of PC1 against PC2 (a) and PCA loadings on PC1 (b).

Figure 7: PCA loadings on PC2.

Figure 8 : PLS-DA prediction plot.

Figure 9: Prediction of the medieval cow tibia sample in the PLS-DA model.

Figure 10: PLS-DA predictions for the samples from sub-layers of unit 15. Specimens identified by unique ID (e.g., N4.42) followed by sub-layer (e.g., 15.2).

Figure 11: PLS-DA predictions for samples from layer AC (COL-).

Figure 12: PLS-DA predictions for samples from layer 4a (COL+). 


\section{Table captions}

Table 1: Confusion matrix of the PLS-DA model applied to the validation set. 

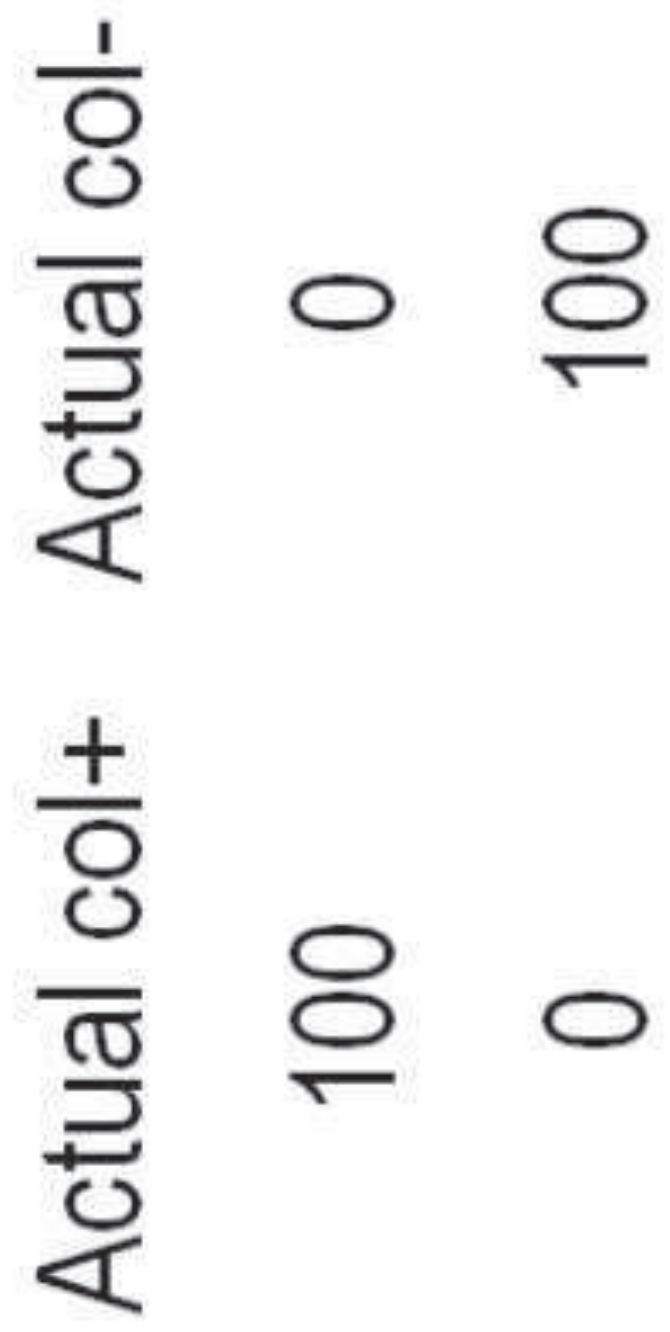

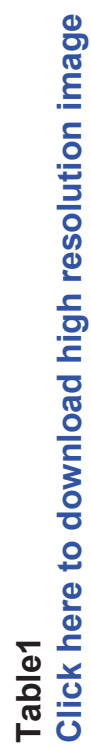

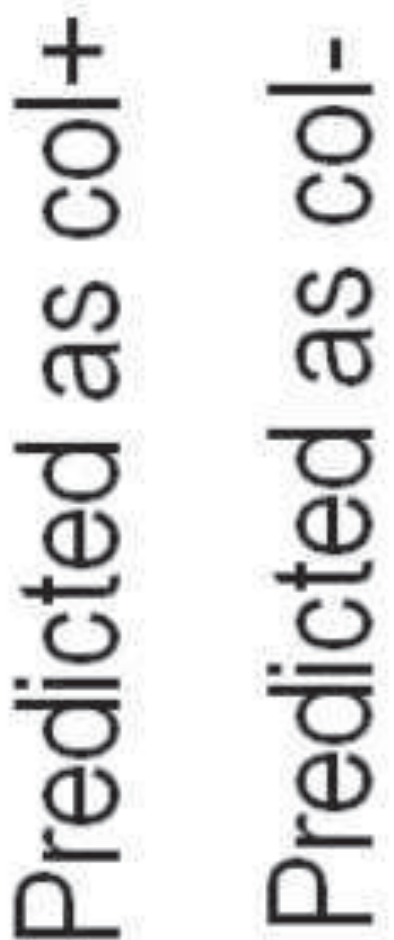



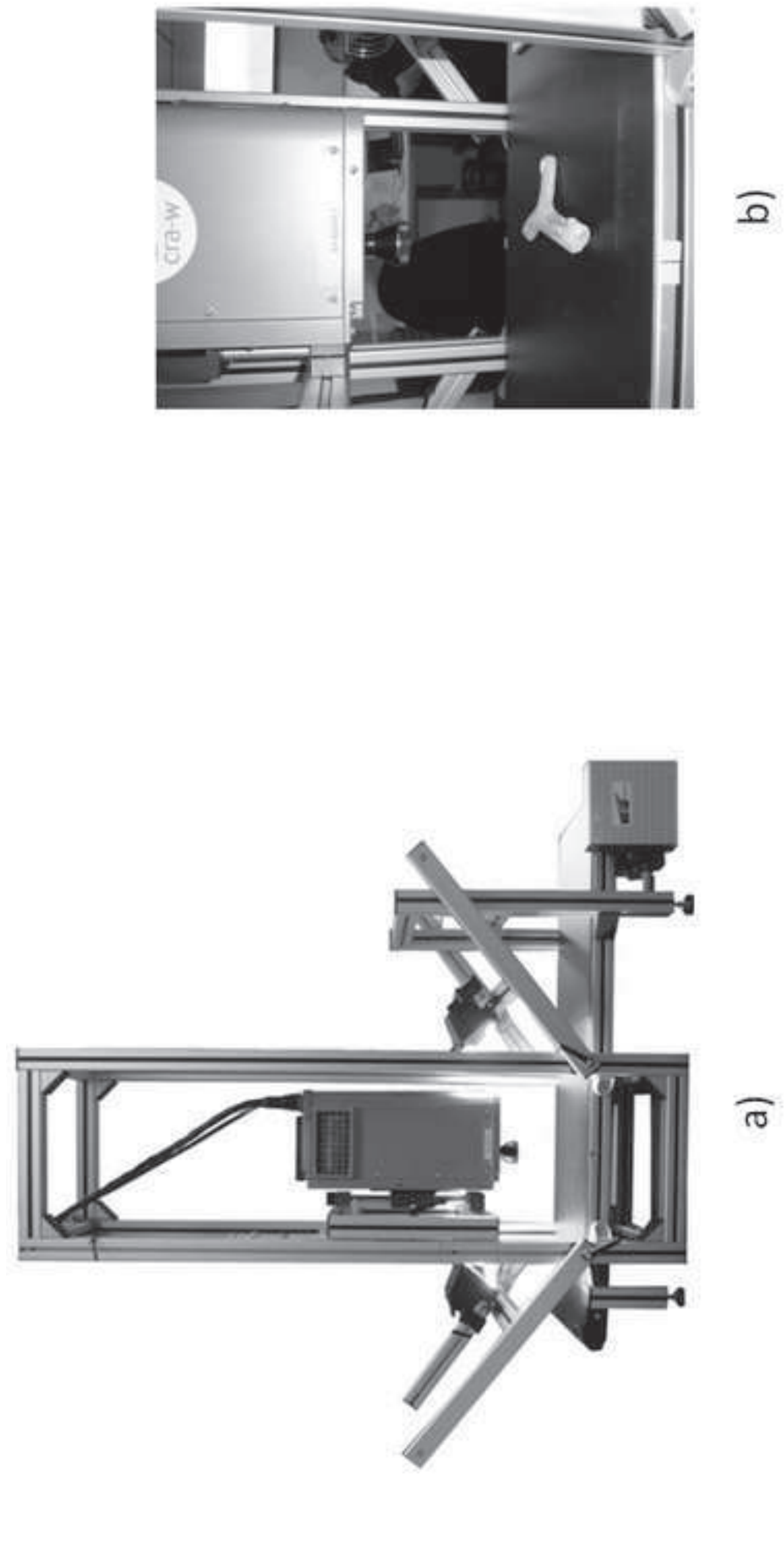


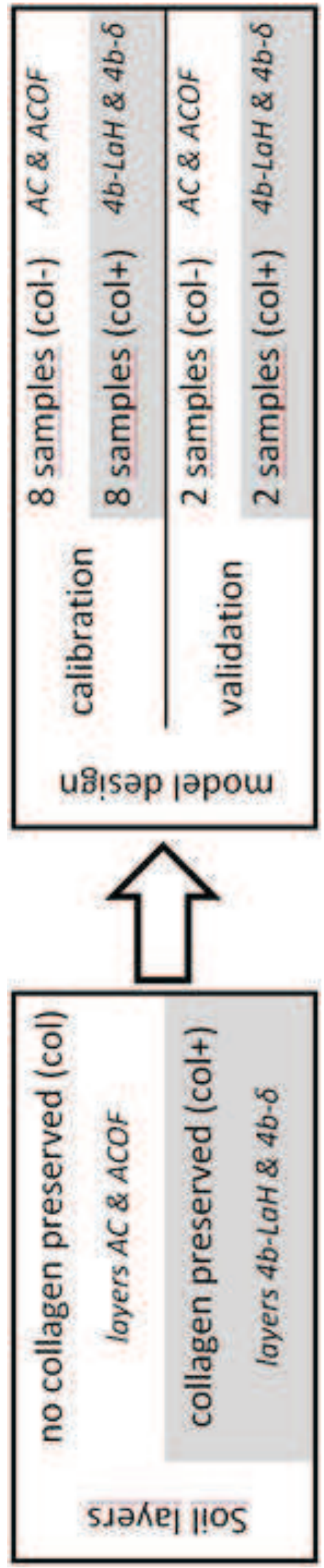

旁产 

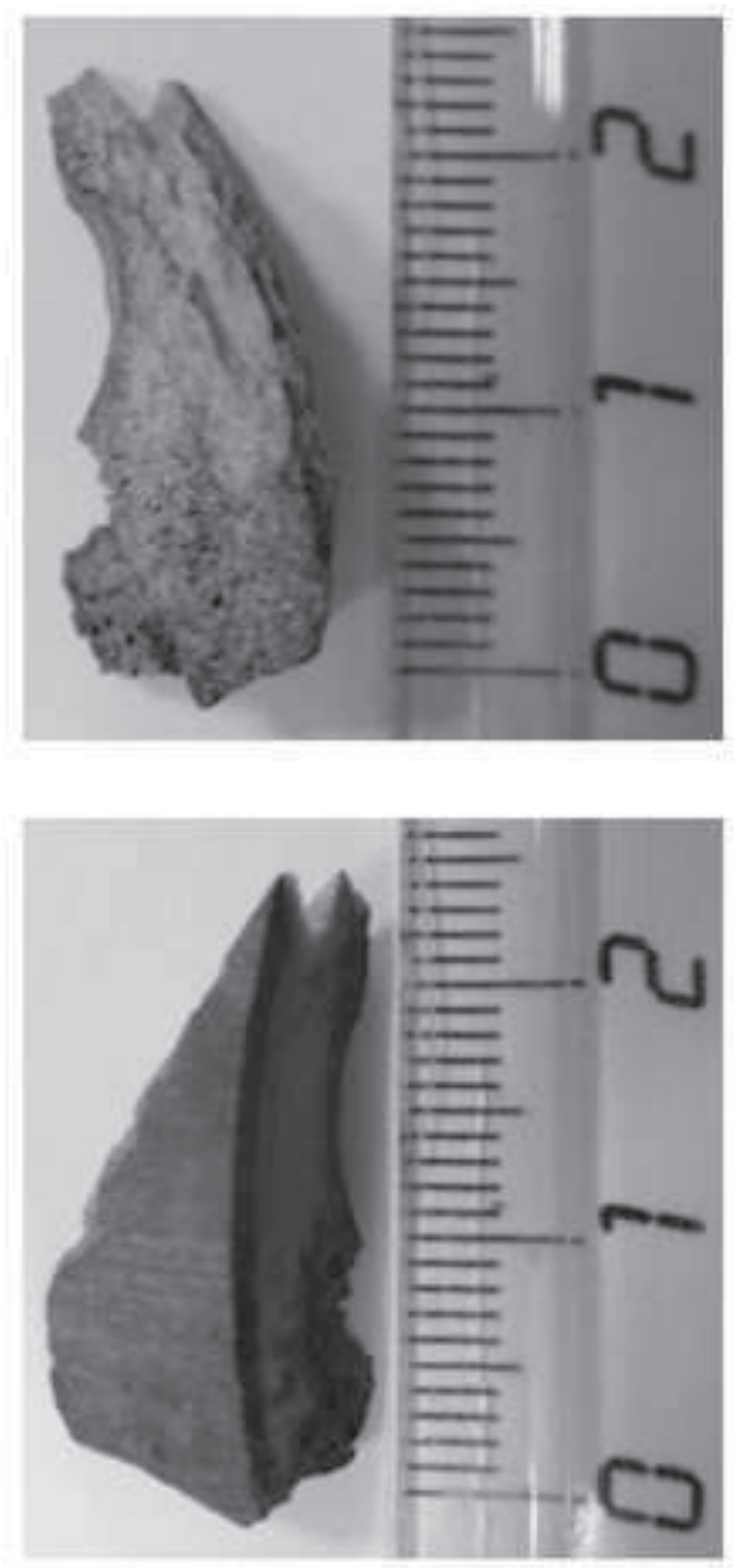

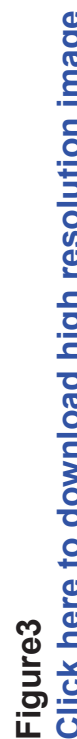

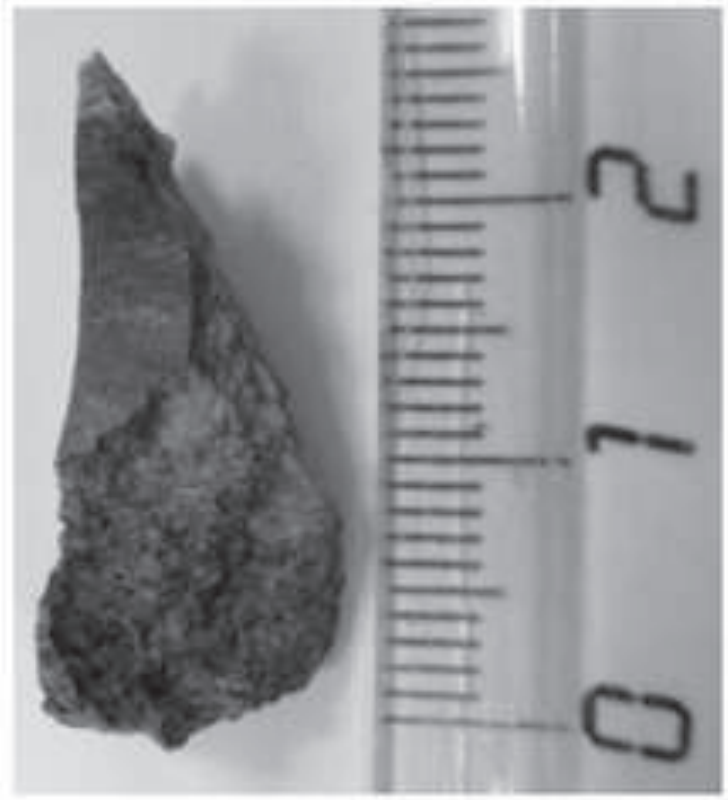




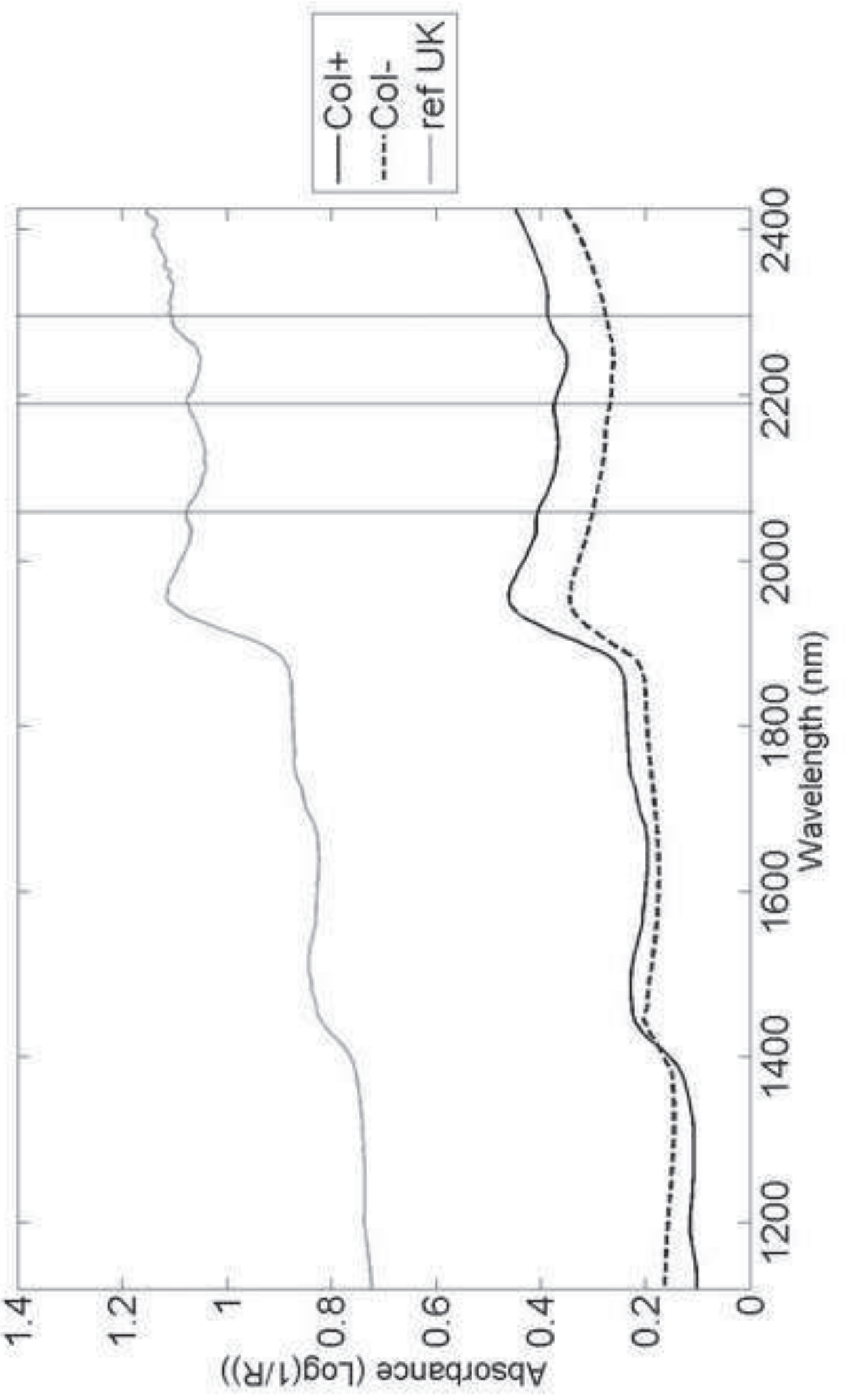




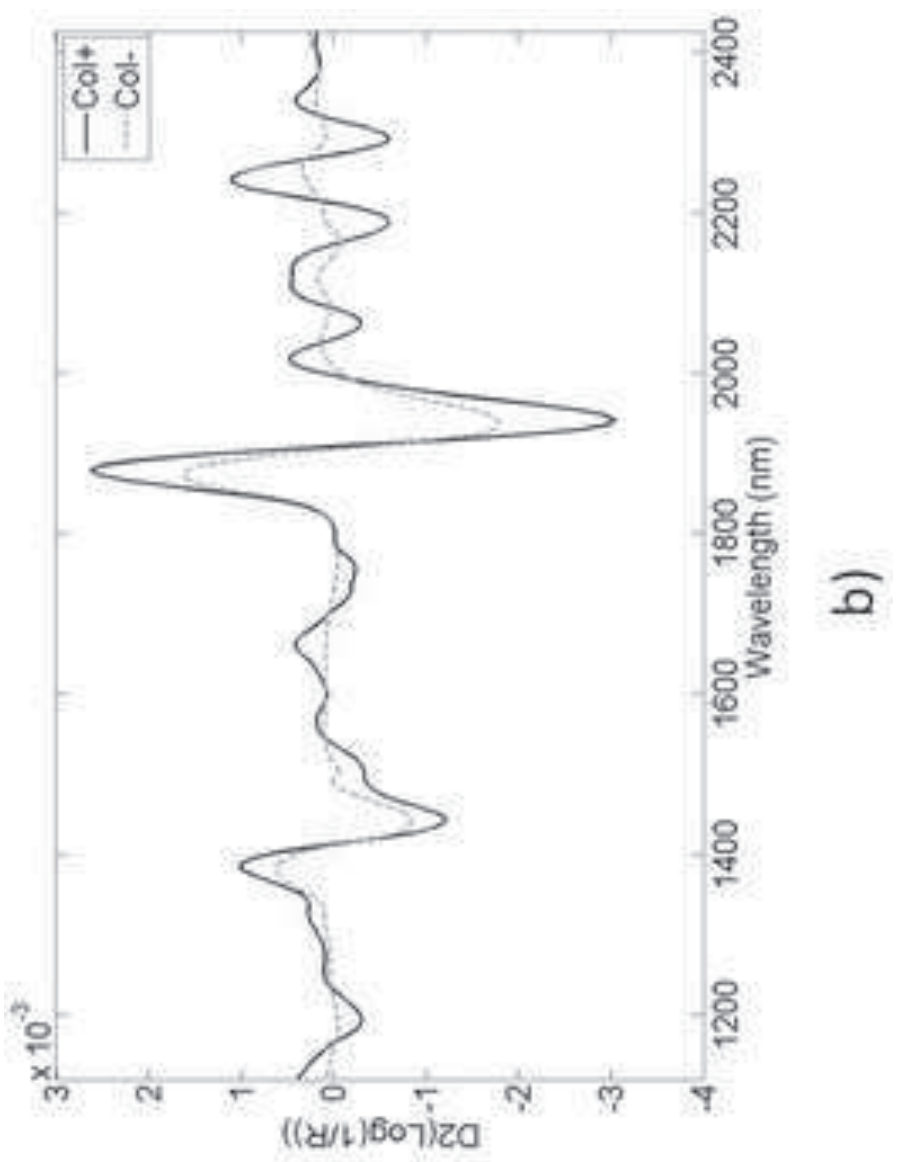

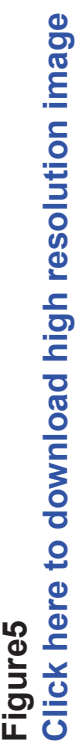

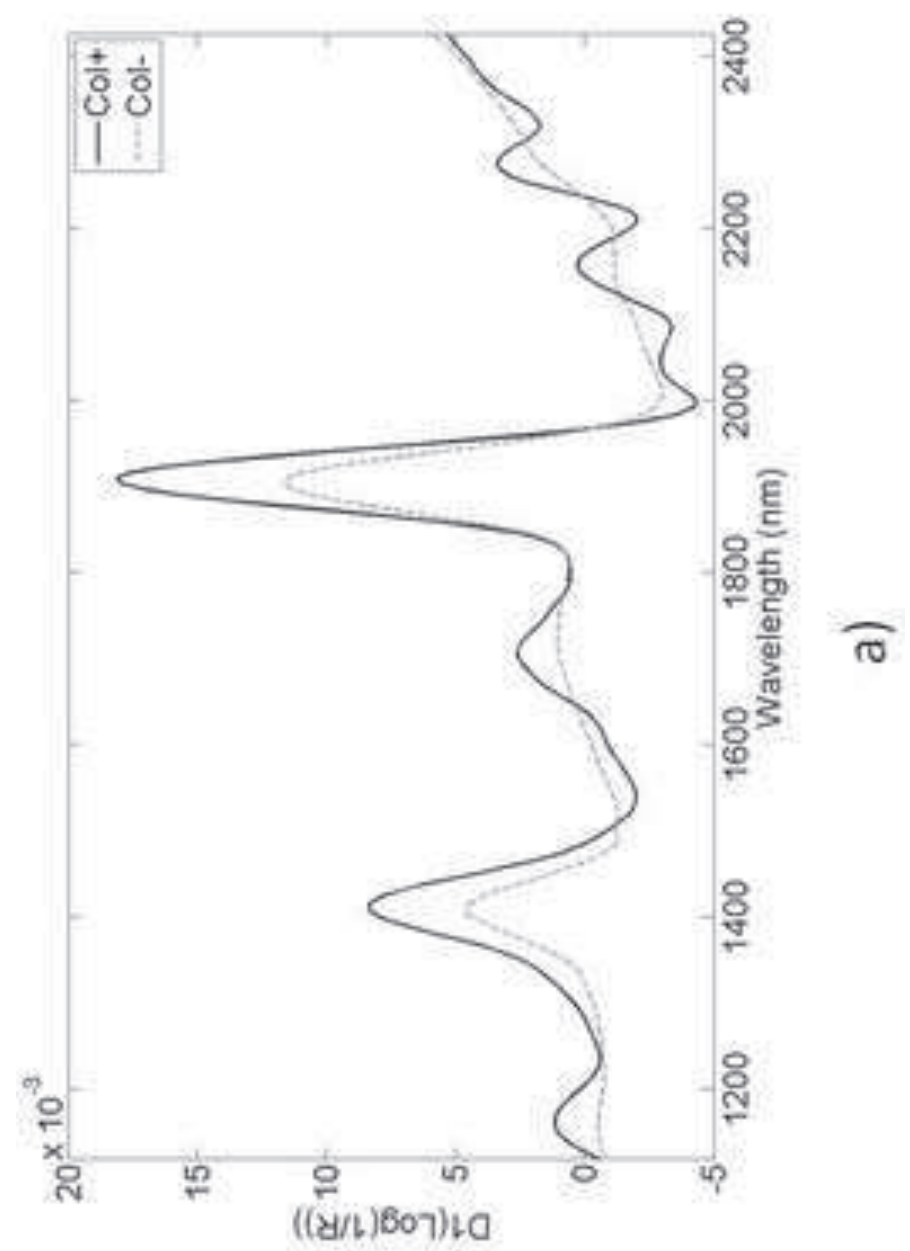




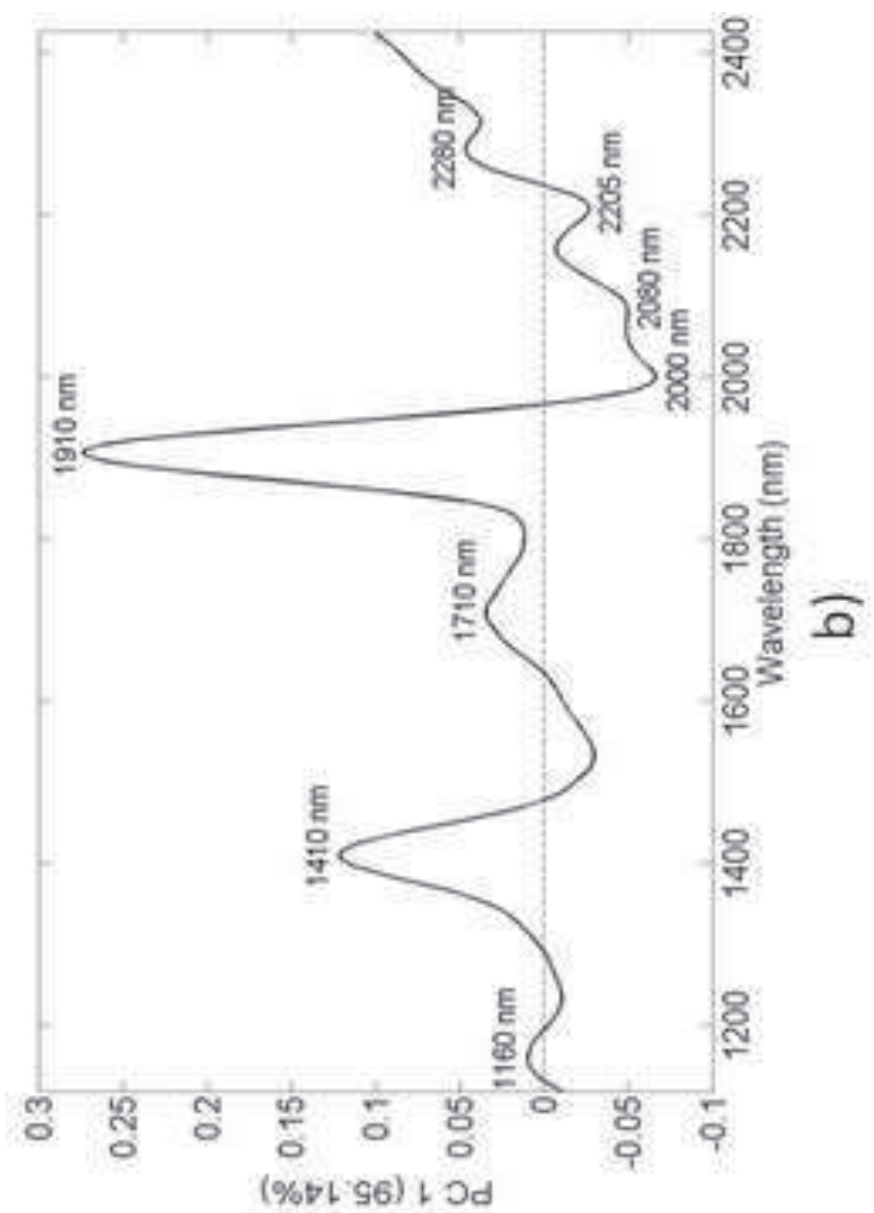

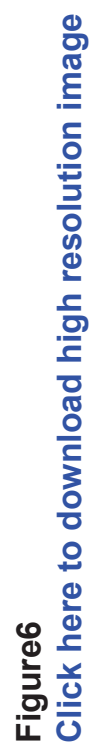

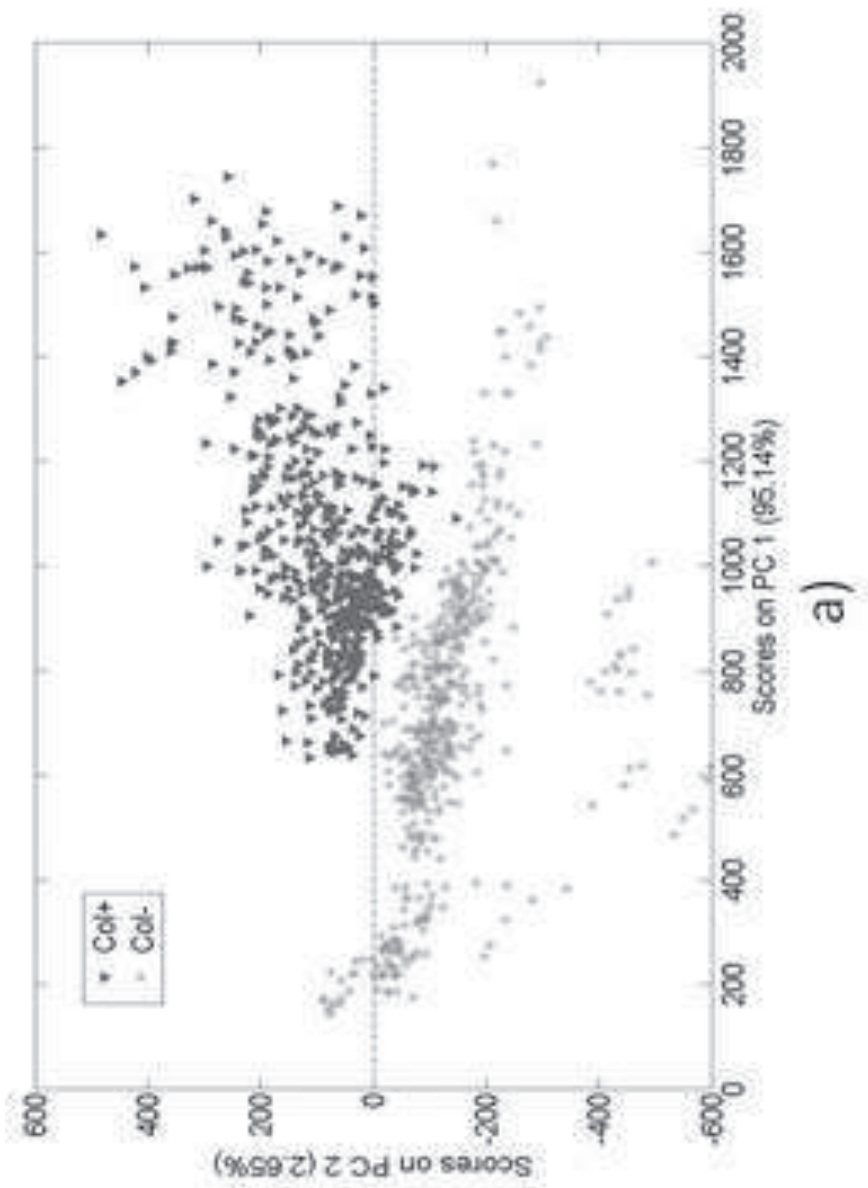




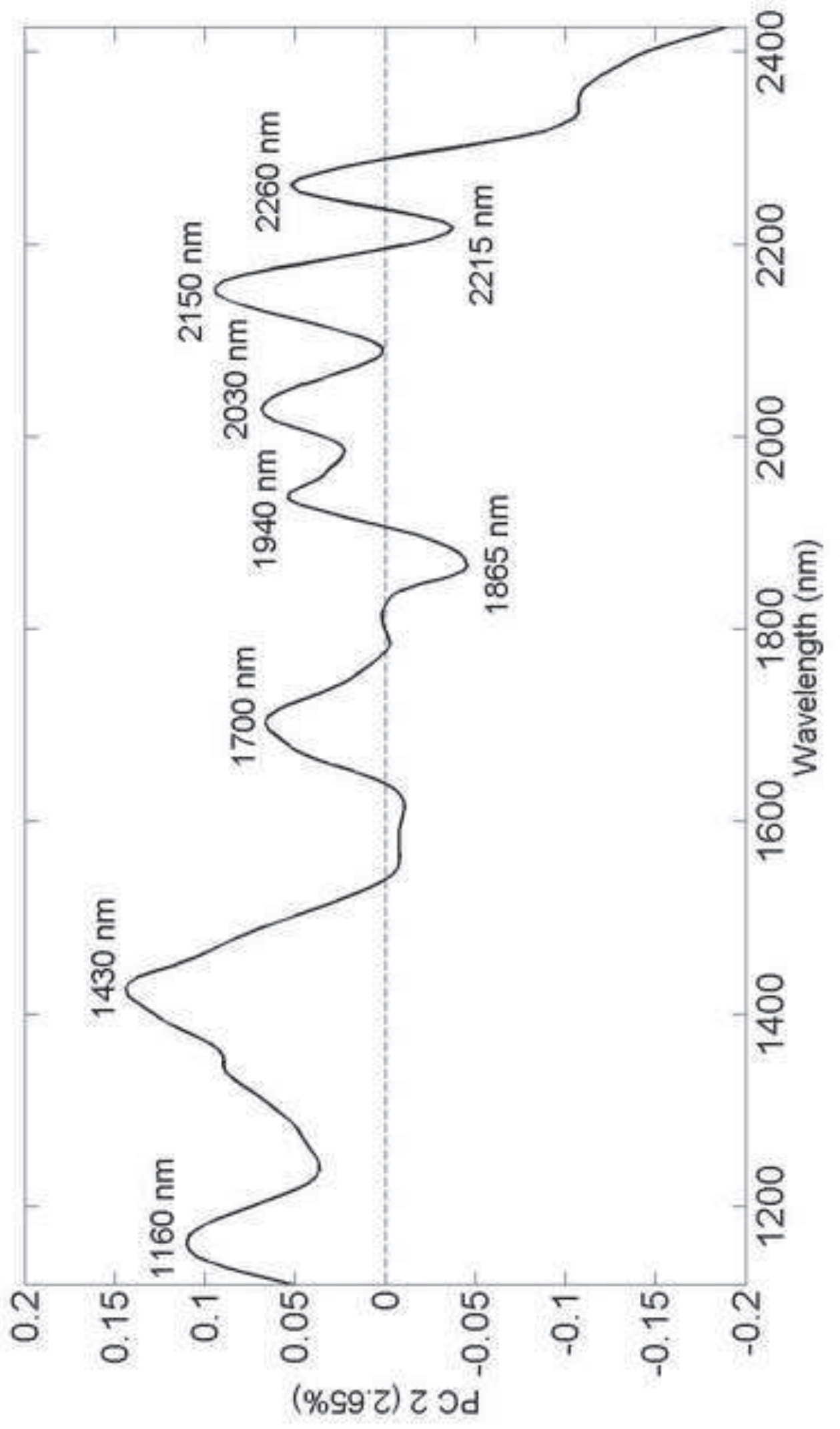




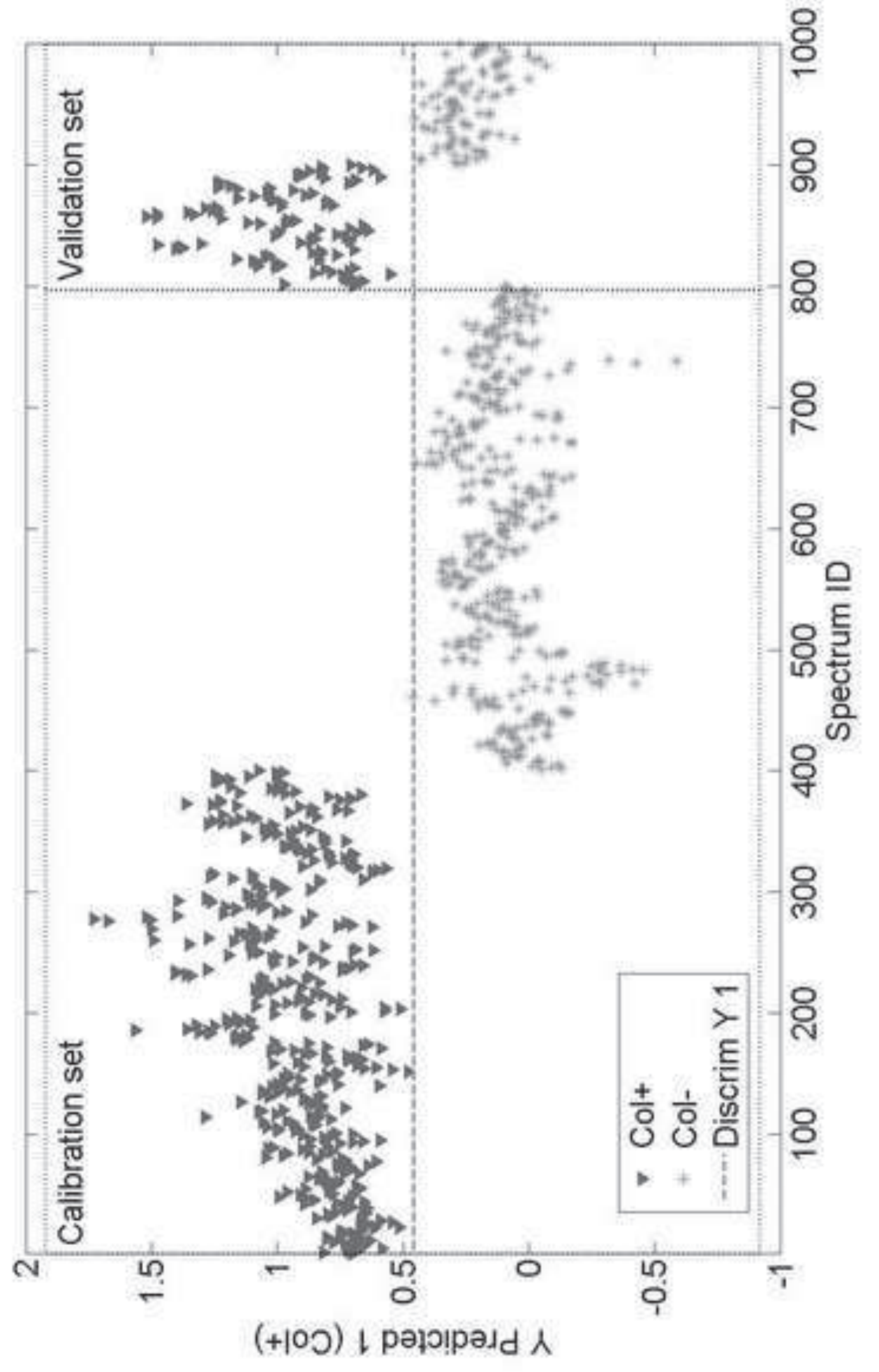




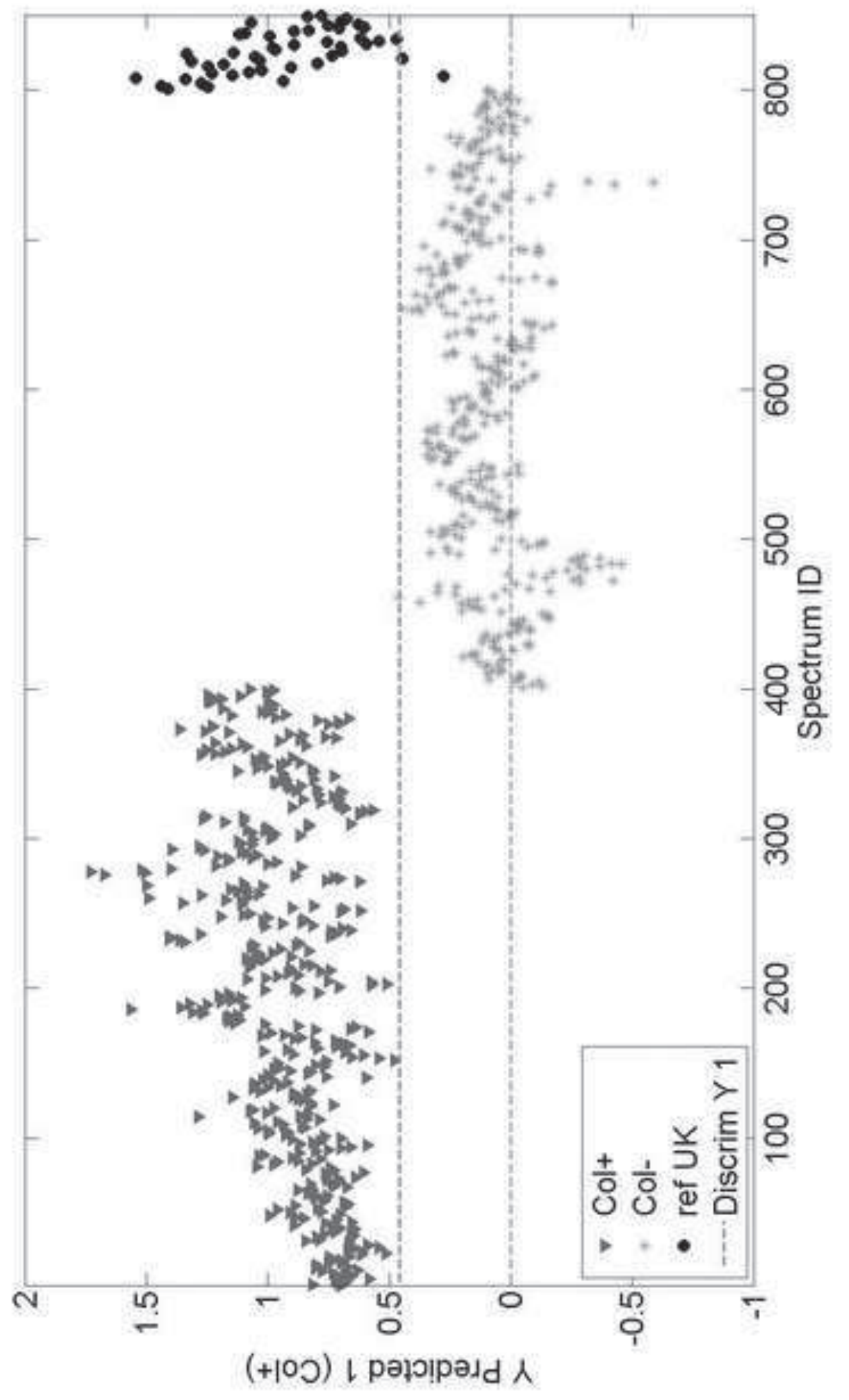




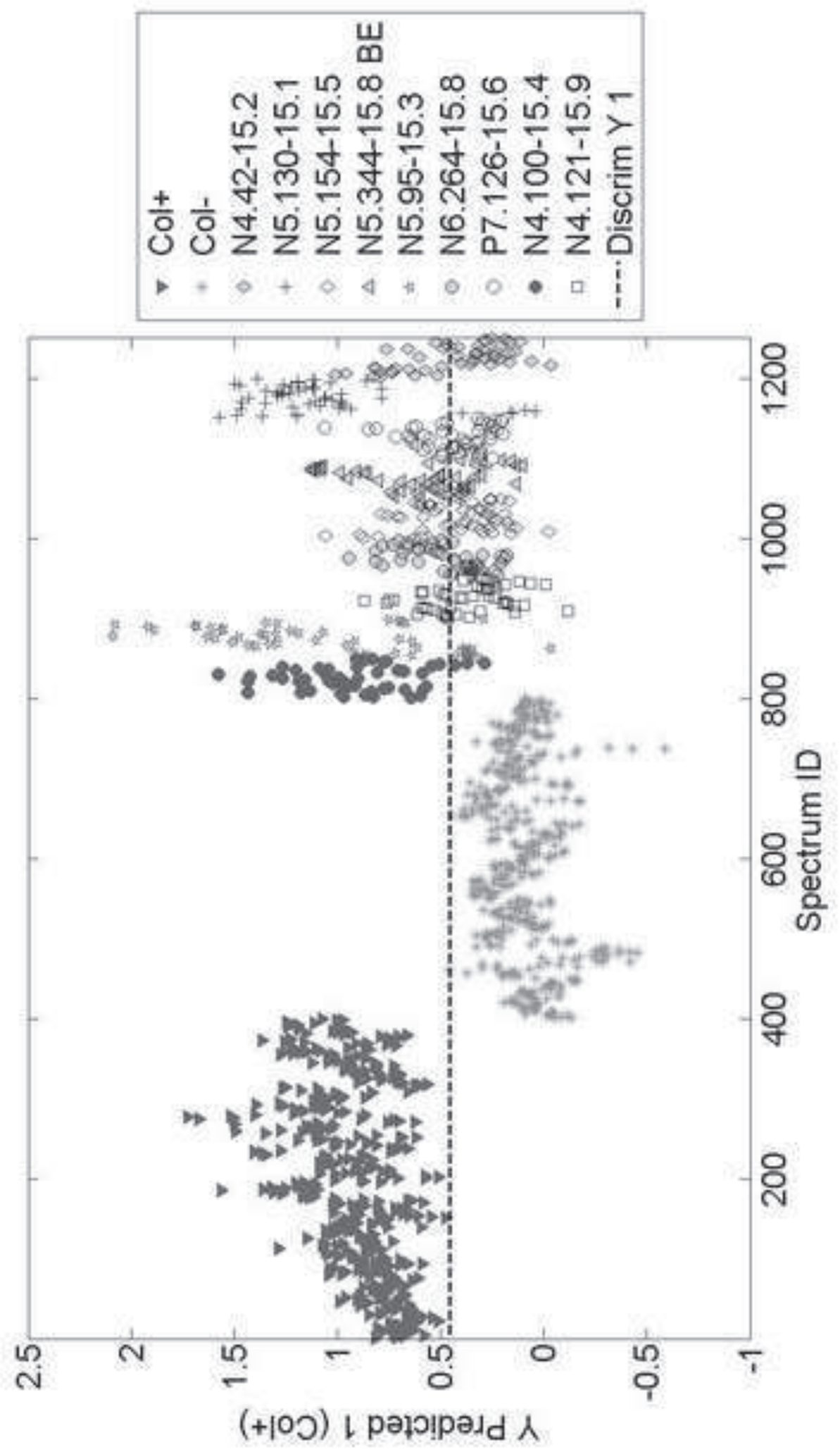




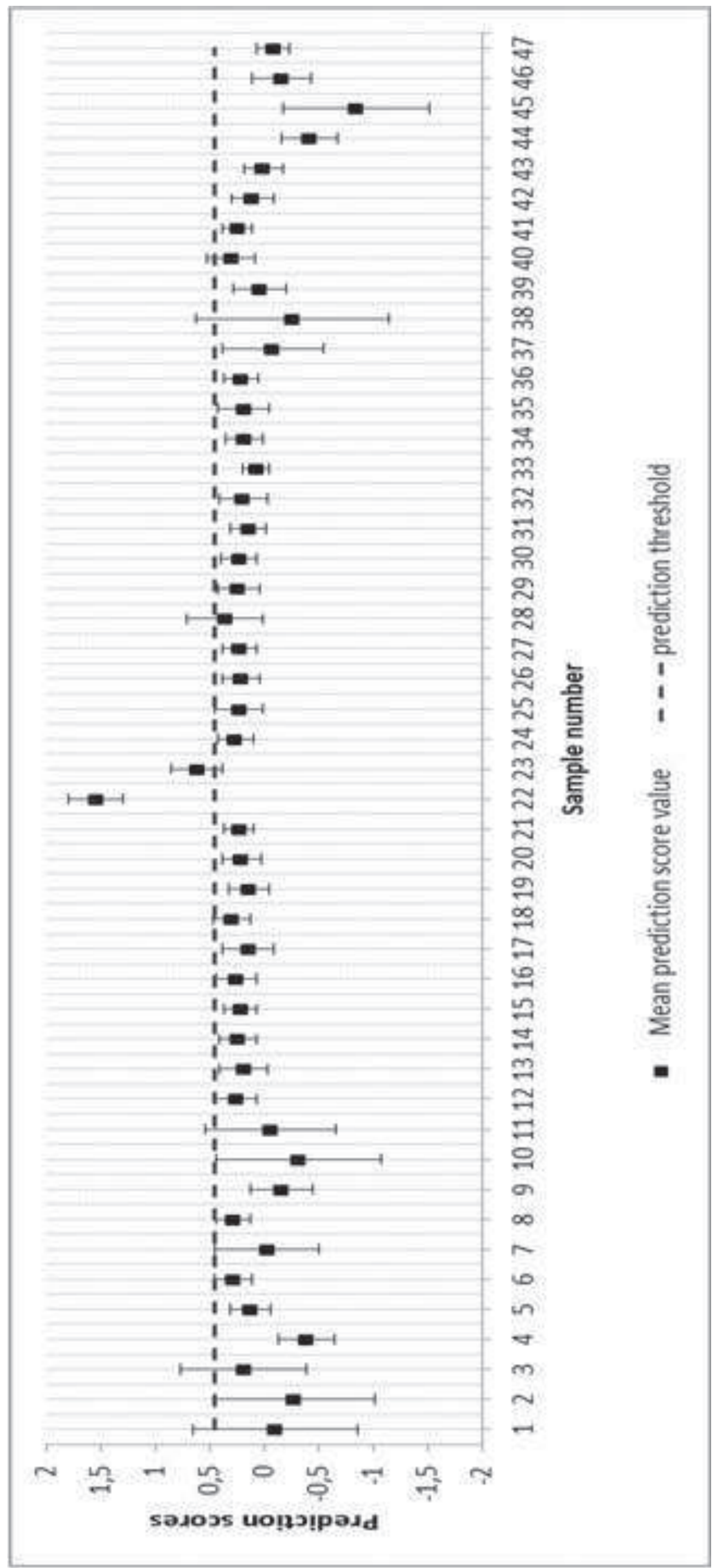

ᄃ

은

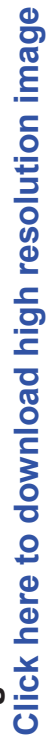




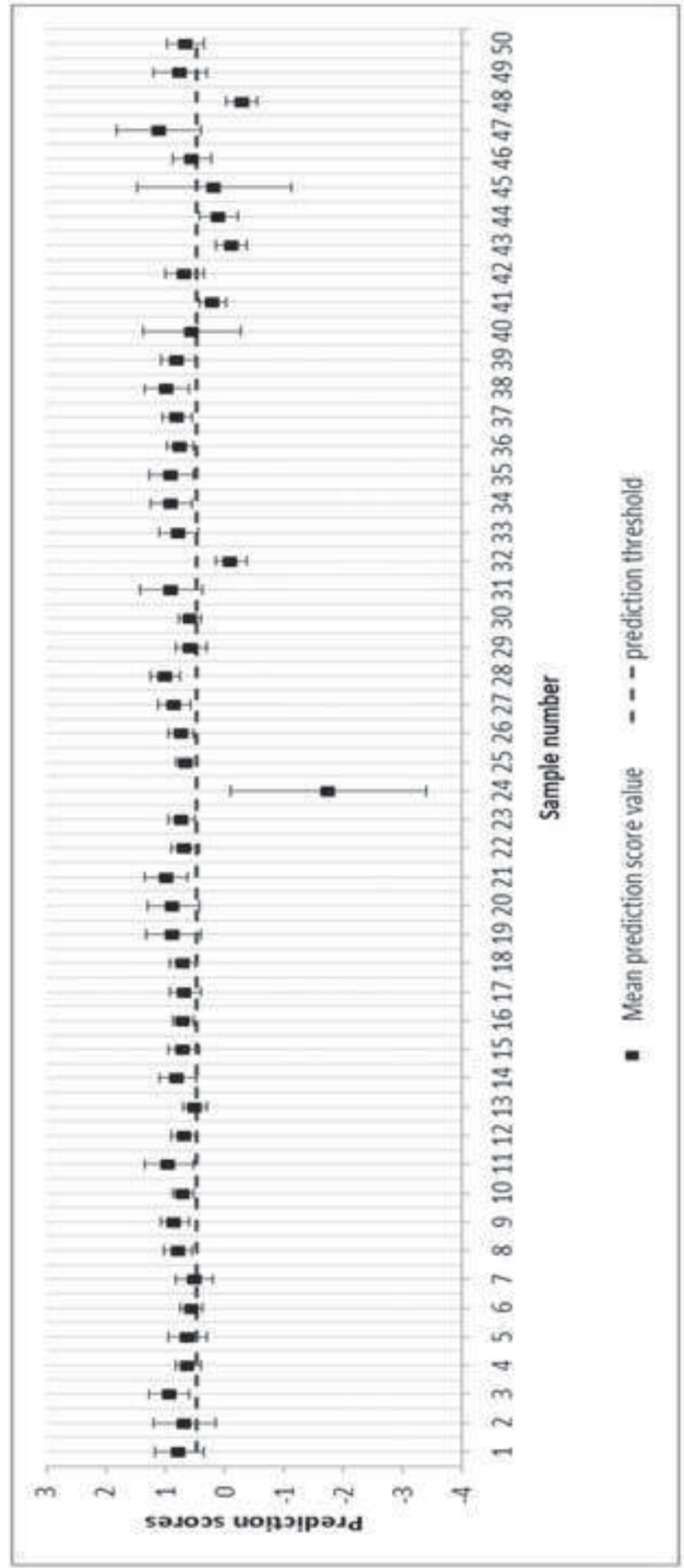

늘 


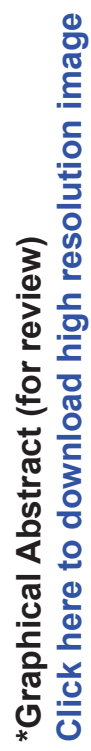

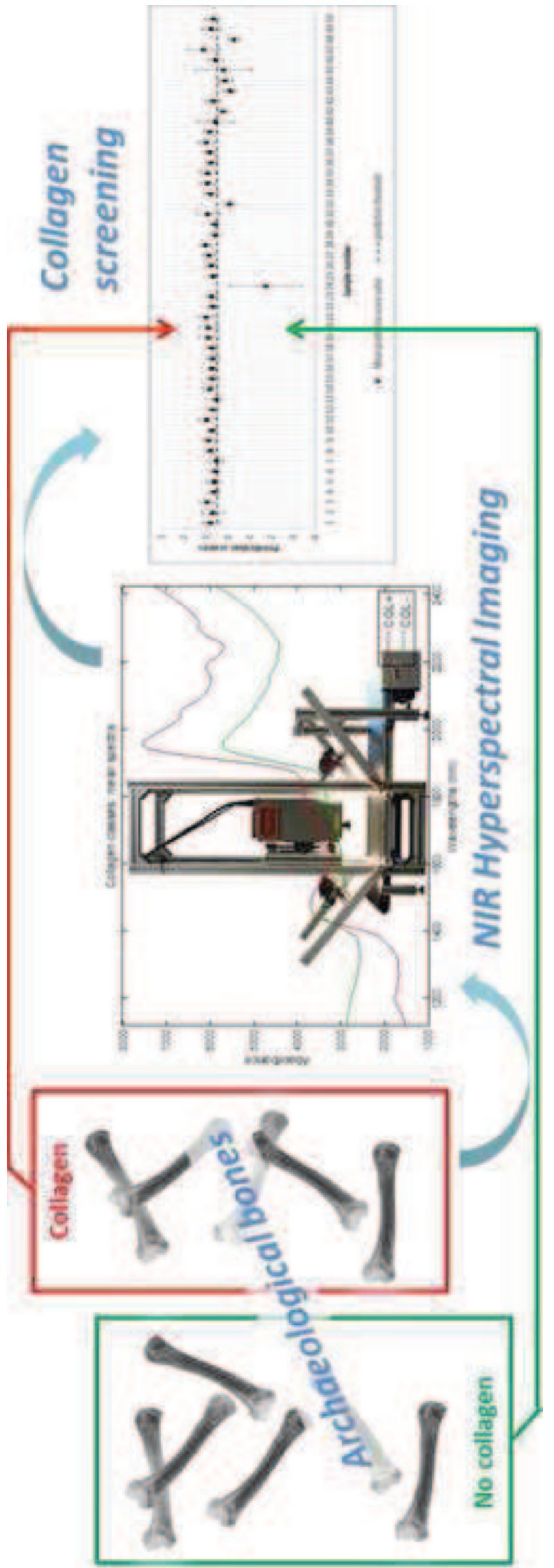

